\title{
Oral Health Status among the Older Population in South Kerala
}

\author{
Reethu Salim(
}

\begin{abstract}
Context: The world population is aging; the proportion of older people is increasing at a faster rate than that of any other age-group. Oral health of the older population is a global concern, which involves a high prevalence of missing teeth, dental caries, periodontal disease, and wasting diseases. Poor oral health and poor general health are interrelated, due to common risk factors. Studies show that the burden of oral diseases among older people in India is high. We attempted to assess the oral health status among older population in South Kerala using the World Health Organization (WHO) oral health assessment tool.

Aims: The aim of the study was to assess the oral health status of older people residing in South Kerala.

Settings and design: The study is a population-based cross-sectional survey conducted among older population in South Kerala.

Methods and materials: A community-based cross-sectional study in which 399 people participated, of which 200 were females and 199 males. People above 60 years who were permanent residents of the district and of diverse socioeconomic status were recruited into the study. The sampling method used was circular systemic random sampling. Clinical examination was done according to WHO criteria.

Statistical analysis used: Descriptive statistics was used in the data. $p \leq 0.05$ was considered significant. Student's $t$-test was used to find the association between variables.

Results: The mean age of the subjects was $65 \pm 5.5$. The mean decayed missing filled teeth (DMFT) was $8.78 \pm 8.3$, and the mean missing teeth score was $7.38 \pm 8.5$. The mean decayed score was $1.3 \pm 1.96$.

Conclusion: The oral health of the study population was generally poor, and their treatment needs were high. Therefore, efforts should be taken to bridge the gap between demand and supply of oral healthcare needs among older population.

Key messages: The present study shows that the burden of oral diseases in older population is high, based on the high number of dental caries, periodontitis, and missing teeth. The complications of oral diseases can be prevented by early detection, treatment, and proper oral hygiene practices.
\end{abstract}

Keywords: Dental caries, Dental diseases, Older population, Oral health status, Periodontal diseases.

Journal of Oral Health and Community Dentistry (2021): 10.5005/jp-journals-10062-0111

\section{INTRODUCTION}

The famous Roman poet Ausonius said about old age: "Let us never know what old age is. Let us know the happiness time brings, not count the years." As a person ages, the valuable ingredient that accompanies is the wisdom. The respected older person processes an intuitive knowledge of how to judge a situation and make necessary and appropriate decisions based on their life experience. ${ }^{1}$ Older people are increasingly seen as contributors to the development of society, with abilities to act for the betterment of themselves and the community at large. However, many countries are likely to face economic and financial burden in relation to public systems of healthcare, pensions, and social protections because of a growing older population. ${ }^{2-4}$

The world population is aging; the proportion of older people is increasing at a faster rate than that of any other age-group. According to data from World Population Prospects, one in six people in the world will be over age 65 (16\%) by 2050, up from one in 11 in 2019 (9\%). According to the census 2011, there are nearly 104 million older persons aged 60 and above in India. The proportion of older population had increased from $5.6 \%$ in 1961 to $8.6 \%$ in 2011. About $71 \%$ of the older population are residing in rural parts of the country. ${ }^{5}$

In most respects, population aging is a testimony of the great success in healthcare. The challenge policy makers are going to face in the coming years is dealing with the diseases of old age. The systemic diseases and oral diseases share common risk factors. Oral
Department of Health Sciences, Sree Chitra Tirunal Institute for Medical Sciences and Technology, Thiruvananthapuram, Kerala, India

Corresponding Author: Reethu Salim, Department of Health Sciences, Sree Chitra Tirunal Institute for Medical Sciences and Technology, Thiruvananthapuram, Kerala, India, Phone: +91 9947074473, e-mail: reethusalim123@gmail.com

How to cite this article: Salim R. Oral Health Status among the Older Population in South Kerala. J Oral Health Comm Dent 2021;15(3):117-121. Source of support: Nil

Conflict of interest: None

health of the older population is a global concern, which involves a high prevalence of missing teeth, dental caries, periodontal disease, and wasting diseases. According to the World Health Organization (WHO), oral health is an integral part of general health and wellbeing, and an important determinant of quality of life (QoL). ${ }^{6}$

In general, poor oral health among older people is reflected as a high prevalence of missing teeth, dental caries, periodontal disease, teeth sensitivity, and oral cancer. The negative impact of poor oral conditions on daily life is particularly significant among older people. Extensive tooth loss reduces chewing performance and affects food choice. Poor oral health and poor general health are interrelated, mainly because of common risk factors; for example, 
severe periodontal disease is associated with diabetes mellitus, ischemic heart disease, and chronic respiratory disease. Tooth loss has also been linked with an increased risk of stroke. Studies done in developing countries revealed that access to oral health services is limited and teeth are often extracted because of pain or discomfort. 6

Research had been done on various parts of the country to assess the oral health status of older people. The cross-sectional survey done by Doifode et al on 5,061 older people revealed that dental caries (43.2\%) and periodontal diseases (34.8\%) were the most common dental disorders. ${ }^{7}$ A nationwide survey conducted by Dental Council of India (DCl) on 18,233 older people from 19 states of the country reported a prevalence of 85 and $80 \%$ among the 65-year to 74-year-olds for dental caries and periodontal disease, respectively. ${ }^{8}$ The burden of oral diseases on older people was mentioned in multicenter studies done in various parts of rural and urban India. These studies report a high prevalence of dental caries, periodontal diseases, and missing teeth. ${ }^{9}$ A study conducted among older residents in geriatric homes reported that 86.3 and $88.0 \%$ of the subjects had no prosthesis in the upper and lower arch, respectively. ${ }^{10}$ Similar finding was found by Shenoy et al. in a study conducted in geriatric homes in Mangalore, which reported that $88 \%$ of the subjects were fully edentulous and only $12 \%$ had complete dentures; another study conducted among older people revealed a high burden of unmet oral healthcare needs. ${ }^{11}$

Studies show that the burden of dental diseases among older people in India is high. We attempted to assess the oral health status among older population in South Kerala using WHO oral health assessment tool.

\section{Subjects and Methods}

A community-based cross-sectional study in which 399 older people participated, of which 200 were females and 199 males. The inclusion criteria used in the study were as follows: minimum age of 60 years and a permanent resident of Kerala. People who were not willing to provide a consent and people with dementia were excluded. The participants were recruited from rural and urban areas of the district. The sampling method used was circular systemic random sampling. That is, the total numbers of older people were divided by the number of people required in each category (rural and urban) to identify the sampling interval in each category. In each category, the first person will be identified by random number from one to the last number corresponding to the last person in the list and the random number was selected. The person who corresponds to the random number was selected from the list. Successive participants were selected from the list in a circular manner by adding sample interval successive to the first random number.

Sample size, $n=[\mathrm{DEFF} \times N p(1-p)] /\left[\left(d^{2} / Z^{2}{ }_{1-\mathrm{a} / 2} \times(N-1)+p \times(1-p)\right]\right.$

Using the following parameters:

Population size (for finite population correction factor or $\mathrm{fpc}$ ) (N): 350012

Hypothesized \% frequency of outcome factor in the population (p): $71 \% \pm 5$ (unmet need for dental extraction from a previous study in a rural population). ${ }^{12}$

Confidence limits as \% of 100 (absolute $\pm \%)(d): 5 \%$

Design effect (DEFF): 1

As calculated in OpenEpi statistical software, at a 95\% confidence level, the required sample size was 317 older people from the whole district. The sample was enhanced by $20 \%$ to accommodate the nonresponse rate and rounded to whole numbers.

The study was approved by the Institute Ethics Committee of Sree Chitra Tirunal Institute for Medical Sciences and Technology, Thiruvananthapuram, Kerala. The study was done in Kollam district. There are 68 Grama Panchayath in Kollam district. There are five urban areas which constitutes corporation and municipality. Each area was numbered separately, and a random number was generated (lottery method) for both urban and rural areas. The urban area selected was Kollam Corporation, and the rural area selected was Kalluvathukkal Grama Panchayath. The urban participants are selected from Kollam Corporation and rural participants from Kalluvathukkal Grama Panchayath. The study population were subjected to an interviewer-administered questionnaire to assess sociodemographic data, followed by oral examination using WHO oral health assessment form-2013 to assess the oral health status. The oral assessment was carried out using community periodontal index (CPI) probe and mouth mirror in natural light. The dentition status, dental caries (DMFT), periodontal status (CPI INDEX), oral mucosal lesions, dental erosions, and dentures were recorded. The data were entered and analyzed using statistical package, SPSS/Version 17. Descriptive statistics, Chi-square tests, and multivariate analysis were used in the data. $p \leq 0.05$ was considered significant. Student's $t$-test was used to find the association between variables. A multivariate analysis was undertaken to evaluate the relationship of the variables.

\section{Results}

A total of 399 patients participated in the study. All the participants had completed the questionnaire and had undergone oral examination. The mean age of the participants was $65.3 \pm 5.5$ (Table 1).

The mean DMFT was 8.78 (SD = 8.38) (Table 2). The major portion of the caries experience was missing teeth with mean

Table 1: Sociodemographic characteristics of the study population

\begin{tabular}{|c|c|c|c|}
\hline SI. No. & Characteristics & Categories & Frequency n (\%) \\
\hline 1 & $\begin{array}{l}\text { Age } \\
(65.3 \pm 5.5)\end{array}$ & $\begin{array}{l}60-69 \text { years } \\
70-79 \text { years } \\
80-89 \text { years }\end{array}$ & $\begin{array}{c}302(76.2) \\
88(21.5) \\
9(2.2)\end{array}$ \\
\hline 2 & Marital status & $\begin{array}{l}\text { Married } \\
\text { Others }\end{array}$ & $\begin{array}{c}372(92.3) \\
27(6.7)\end{array}$ \\
\hline 3 & Education status & $\begin{array}{l}\text { Post-graduation } \\
\text { Graduation } \\
\text { Completed secondary } \\
\text { education } \\
\text { Competed } \\
\text { matriculation } \\
\text { Primary education } \\
\text { No formal education }\end{array}$ & $\begin{array}{c}8(2.0) \\
60(14.8) \\
64(16.0) \\
159(40.3) \\
107(26.8) \\
1(0.3)\end{array}$ \\
\hline 4 & Occupation & $\begin{array}{l}\text { Office work } \\
\text { Skilled } \\
\text { Semi-skilled } \\
\text { Unskilled } \\
\text { Presently unemployed }\end{array}$ & $\begin{array}{c}44(11.0) \\
41(10.0) \\
32(8.3) \\
128(32.3) \\
154(38.5)\end{array}$ \\
\hline 5 & Income & $\begin{array}{l}\text { AY } \\
\text { BPL } \\
\text { APL }\end{array}$ & $\begin{array}{c}39(9.8) \\
208(52.1) \\
152(38.0)\end{array}$ \\
\hline 6 & Systemic diseases & Present & $274(68.7)$ \\
\hline
\end{tabular}


Table 2: DMFT index

\begin{tabular}{llcc}
\hline & Variable & Mean & SD \\
\hline 1 & Decayed teeth $(\mathrm{dt})$ & 1.30 & 1.96 \\
2 & Missing teeth $(\mathrm{mt})$ & 7.39 & 8.55 \\
3 & Filled teeth $(\mathrm{ft})$ & 0.12 & 0.65 \\
4 & DMFT & 8.78 & 8.38 \\
\hline
\end{tabular}

Table 3: Mean and standard deviation of DMFT according to sociodemographic characteristics

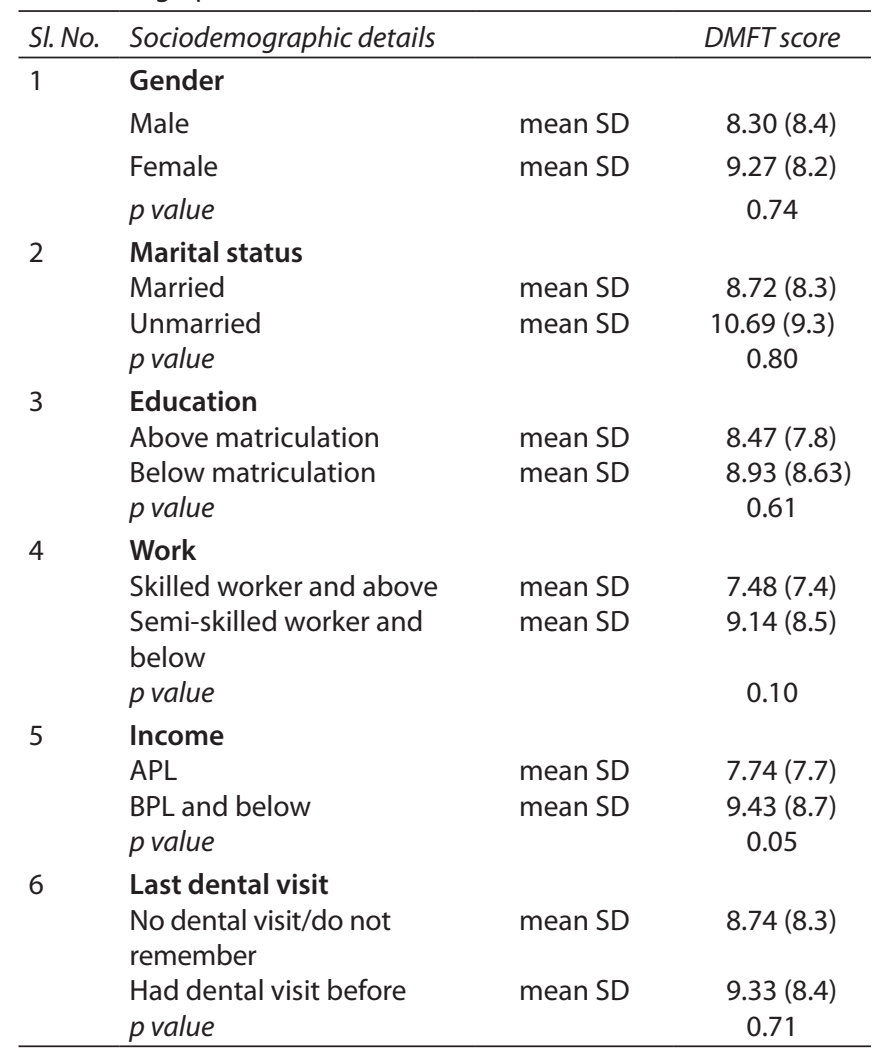

Table 4: Oral health status of study population

\begin{tabular}{llc}
\hline SI. No. & \multicolumn{1}{c}{ Variable } & Percentage \\
\hline 1 & Subjects who have or have had & $209(52.4)$ \\
& caries of permanent teeth & \\
2 & Subjects with untreated caries & $198(49.6)$ \\
3 & People with natural teeth & $377(94.5)$ \\
& People without natural teeth & $22(5.5)$ \\
4 & People with healthy periodontal & $273(68.4)$ \\
& Conditions & \\
5 & People with gingival bleeding & $182(45.6)$ \\
6 & People with pocket ( $\geq 6$ mm) & $91(22.9)$ \\
7 & Number and percentage of teeth & $117(31)$ \\
& present with pockets (4-5 mm) & $184(48.8)$ \\
8 & Sensitivity & $390(97.7)$ \\
9 & No abnormalities in oral mucosa & $9(2.3)$ \\
& Oral mucosal lesions present & $10(2.5)$ \\
10 & Partial denture in upper arch & $16(4)$ \\
11 & Partial denture in lower arch & $16(4)$ \\
& Complete denture in upper arch & $14(3.5)$ \\
\hline
\end{tabular}

7.39, while decay and filled teeth accounted for $1.30 \pm 1.96$ and $0.12 \pm 0.65$, respectively.

A significant association ( $p \leq 0.05$ ) was found between income and DMFT status among older population. No association was found between gender, marital status, education, work, and last dental visit (Table 3).

The results show 377 (94.5) people with natural teeth. The number of people with untreated dental caries is 198 (5.5). There are 273 (68.4) people with healthy periodontal condition. The number of people with gingival bleeding is 182 (45.6), and 91 (22.9) people had periodontal pocket during examination. There are 10 (2.5) percentage of people with partial denture in the upper arch and 16 (4) percentage of people with partial denture in the lower arch. This study couldn't find any older people with no dental problem (Table 4).

\section{Discussion}

The burden of dental caries in older population is high in India, as seen from individual studies as well as from weighted prevalence. The prevalence varied in different parts of the country, and this may be attributed to different study settings, study populations, differences in eating habits, oral hygiene habits, fluoride content in the water, etc. The DMFT index was used to assess the caries severity and distribution. The mean DMFT in this study was $8.78 \pm 8.38$. The major portion of the caries experience was missing teeth with a mean score of $7.39 \pm 8.55$, while decay and filled teeth accounted for $1.30 \pm 1.96$ and $0.12 \pm 0.65$, respectively. Most of the studies used DMFT index for estimating the prevalence of dental caries. There was a high score of missing teeth, as reported from most of the studies, which indicates that decayed teeth or loose teeth due to periodontitis were generally extracted when in pain. The DMFT scoring does account for teeth lost for reasons other than decay (such as periodontal disease), which may be the reason for a large number of missing teeth recorded and also a major limitation. The high prevalence of periodontal disease will be a reason for high prevalence of missing teeth (80.9\%). The restorative procedures are rarely performed by the older people, which is due to barriers such as cost of treatment, multiple visits to clinic, and long waiting hours. ${ }^{10}$ The study done by Molate on older people showed a DMFT score of 17 , which was contrary to our study finding. ${ }^{13}$ Various studies done in India have a contradictory result with the present study, which may be due to the regional variation. The DMFT score in a multicentric study of WHO conducted in 2007 was 5.3, which ranged from 2.4 in Rajasthan to 15.5 in Uttar Pradesh. ${ }^{14}$ Patro et al. reported a DMFT score of $13.8^{15}$ and the nation-wide study by the DCl in 2003 reported an average DMFT score of $14.9 .^{8}$ A study from South India among older people reported a mean DMF index of $13.5,^{12}$ which is higher than the results reported in the present study.

The number of subjects who have or have had caries of the permanent dentition was 209 (52.4) and who had untreated caries was 198 (49.6). This result shows that very few people had only undergone any form of restorative treatment. This prevalence of dental caries was much lower than the results reported by Patro et al. $(91.7 \%)^{15}$ and higher than that reported in Nagpur (43.2\%). ${ }^{7}$

The filled teeth score was lower in this study with a mean score of $0.12 \pm 0.65$. This study finding corresponds to the findings from the study conducted by Srivastava et al. ${ }^{9}$ Studies done by Goel et al. and Thomas et al. found no filled teeth. ${ }^{12,16}$ People who needs filling of teeth had either had an unmet need for the treatment of dental caries or could have extracted their teeth, which is much evident 
from the mean score of missing teeth. The mean score of missing teeth in this study accounts for $7.39 \pm 8.5$. This result contradicts with the study conducted by Srivastava et al. ${ }^{9}$ In the present study, the DMFT score was significantly associated with income of the person on bivariate analysis; this shows that people with less income has more need for dental treatment as dental treatment is expensive and it is not affordable for many of them. Therefore, the only treatment option available for the majority of patients with dental caries and periodontal diseases is tooth extraction.

A significant association was found between dental caries and age. As age increases, there are possibility of increase in number of carious teeth. As age increases, due to wear and tear, there will be more abrasion and abfraction defects; gingival recession will be commonly seen in older people and widened contact areas between the teeth, thus increasing the risk caries. There is a tendency of high prevalence of root caries among older people in our country. In addition to that, poor oral hygiene, faulty oral hygiene practices, and use of indigenous oral aids with resultant food impaction between teeth could contribute toward higher prevalence of caries in older people. ${ }^{17}$

The percentage of people with gingival bleeding was 45.6. The number and percentage of people with pathological periodontal pocket ( $\geq 6 \mathrm{~mm}$ ) was 91 (22.9) and with pocket (4-5 mm) was 117 (31). These results correspond to the study done by Sujatha et al. ${ }^{18}$ This result contradicts with the findings of Srivastava et al. ${ }^{9}$ The percentage of periodontal disease can be associated with the number of missing teeth. A high percentage of periodontal disease also contributes to a high rate for missing teeth. As age increases, the prevalence of periodontal diseases increases. From the report of a multicentric study conducted in seven distinct geographic locations in India, a high prevalence of periodontal diseases among older age-groups was found. ${ }^{19}$ Epidemiological studies available at WHO confirm that periodontal disease severity and prevalence tend to be high in older age-groups as compared to younger agegroups. ${ }^{20}$ Furthermore, a multicentric study from India reported a prevalence of gingival bleeding from various parts of the country ranging from 12.3 to $99.8 \%$. Even though the overall lower level is much lower than the results reported in our study. The results of the multicentric study correspond to this present study. ${ }^{14,19}$

In most studies carried out worldwide, significant relationships between socioeconomic status and periodontal disease have been observed; i.e., people with low income contribute to poor periodontal disease status. ${ }^{20,21}$ According to Drury et al., the difference in prevalence and severity of periodontal disease among people of higher and lower socioeconomic status in the United States was $10-20 \% .{ }^{22}$ Considerable differences in the occurrence of periodontal disease are found by the socioenvironmental factors responsible for periodontal disease observed in populations living in definite geographic regions or locations. ${ }^{14}$

The percentage of people with missing teeth was 323 (80.9). This result contradicts the study done in Nellore as the prevalence of missing teeth was $96.18 \% .{ }^{23}$ The reason for a large number of missing teeth is that either people could have extracted teeth due to dental caries or the teeth could have worn out due to periodontal disease. A significant association was found between dental visits and missing teeth $(p<0.001)$. According to the National Oral Health Survey of India 2004, tooth loss among the older people may be due to the cumulative effect of dental diseases and lack of proper oral healthcare measures. This may also reflect on many things that the older people might have experienced in their past, such as high prevalence of oral diseases, unavailability of services, past socioeconomic and cultural conditions, and the nature of dental care provided in earlier days. It has also been reported that age alone is not responsible for the deterioration of oral health. There may be several other factors such as multiple systemic diseases, side effects of medications, and psychological factors leading to neglect of personal and oral hygiene resulting in higher tooth loss among the older age-group. 8,14,23

The number of people with missing teeth is high in this study but the prosthetic status among the study participants is low. People with partial denture comprise 26 (6.5). This result was much lower than the results from the study done in Kochi, Kerala. ${ }^{24}$ It was observed that there were a large number of people who perceived that they had missing teeth but very few had perceived the need for a denture. According to many subjects, dentures were expensive and unaffordable.

Further research in a large sample of population is required to get an exact picture of the burden of oral diseases faced by older people. However, this study could provide a light to problems faced and treatment needs faced by older people.

\section{Conclusion}

The present study shows that the burden of oral diseases in older population is high, based on the high number of dental caries, periodontitis, and missing teeth. The complications of oral diseases can be prevented by early detection, treatment, and proper oral hygiene practices. Oral health policy should be strengthened to improve the oral healthcare services in affordable, accessible, and available manner.

\section{OrCID}

Reethu Salim ๑ https://orcid.org/0000-0001-9693-5705

\section{References}

1. Vital Aging Network. Available from: https://vital-aging-network. org/.

2. World's older population grows dramatically. Natl Inst Health $\mathrm{NIH}$; 2016. Available from: https://www.nih.gov/news-events/newsreleases/worlds-olderpopulation-grows-dramatically.

3. Ghosh S. Equity in the utilization of healthcare services in India: evidence from National Sample Survey. Int J Health Policy Manag 2014;2(1): 29-38. DOI: 10.2139/ssrn.2383884.

4. Singh Z. Universal health coverage for India by 2022: a utopia or reality? Indian J Commun Med 2013;38(2):70-73. DOI: 10.4103/09700218.112430 .

5. Population composition-2011, census of India. Available from: https:// censusindia.gov.in/vital_statistics/SRS_Report.

6. Petersen PE, Yamamoto T. Improving the oral health of older people: the approach of the WHO Global Oral Health Programme. Community Dent Oral Epidemiol 2005;33(2):81-92. DOI: 10.1111/j.16000528.2004.00219.x.

7. Doifode VV, Ambadekar NN, Lanewar AG. Assessment of oral health status and its association with some epidemiological factors in population of Nagpur, India. Indian J Med Sci 2000;54(7):261-269. PMID: 11143844

8. Mathur DV. National oral health survey \& fluoride mapping. 2004. p. 176.

9. Srivastava R, Nongkynrih B, Mathur VP, et al. High burden of dental caries in geriatric population of India: a systematic review. Indian J Public Health 2012;56(2):129. DOI: 10.4103/0019-557X.99903.

10. Shrivastav A, Bhambal A, Reddy V, et al. Dental prosthetic status and needs of the residents of geriatric homes in Madhya Pradesh, India. 2011;3:5. 
11. Shenoy RP, Hegde V. Dental prosthetic status and prosthetic need of the institutionalized elderly living in geriatric homes in Mangalore: a pilot study. ISRN Dent 2011;2011:987126. DOI: 10.5402/2011/987126.

12. Thomas S. Barriers to seeking dental care among elderly in a rural South Indian population. 2011;7:6.

13. Molete MP, Yengopal V, Moorman JD. Oral health needs and barriers to accessing care among the elderly in Johannesburg. SADJ 2014;69(8):352, 354-357. PMID: 26548224.

14. Shah N, Pandey RM, Duggal R, et al. Oral health in India: a report of the multi centric study. Directorate General of Health Services, Ministry of Health and Family Welfare, Government of India and World Health Organisation Collaborative Program; 2007. Corpus ID: 79993002.

15. Patro BK, Ravi Kumar B, Goswami A, et al. Prevalence of dental caries among adults and elderly in an urban resettlement colony of New Delhi. Indian J Dent Res 2008;19(2);95-98. DOI: 10.4103/0970-9290.40460. Available from: http://www.ijdr.in/article.asp?issn=0970-9290.

16. Goel P, Singh K, Kaur A, et al. Oral healthcare for elderly: Identifying the needs and feasible strategies for service provision. Indian J Dent Res 2006;17(1):11. DOI: 10.4103/0970-9290.29897.

17. Shah N, Sundaram KR. Impact of socio-demographic variables, oral hygiene practices, oral habits and diet on dental caries experience of Indian elderly: a community-based study. Gerontology 2004;21(1):43. DOI: 10.1111/j.1741-2358.2004.00010.x. Available from: https://onlinelibrary.wiley.com/doi/epdf/10.1111/j.17412358.2004.00010.x.
18. Sujatha BK, Gomez MS, Mathew NS, et al. Oral health problems among geriatric population and its implication on general health: a crosssectional survey JDent Res Rev 2017;4:13-16.DOI: 10.4103/jdrr.jdrr_26_17. Available from: http://www.jdrr.org/text.asp?2017/4/1/13/209359.

19. Shaju JP, Zade RM, Das M. Prevalence of periodontitis in the Indian population: a literature review. J Indian Soc Periodontol 2011;15(1): 29-34. DOI: 10.4103/0972-124X.82261.

20. Petersen $\mathrm{PE}$, Ogawa $\mathrm{H}$. Strengthening the prevention of periodontal disease: the WHO approach. J Periodontol 2005;76(12):2187-2193. DOI: 10.1902/jop.2005.76.12.2187.

21. Petersen PE, Baehni PC. Periodontal health and global public health. Periodontol 2000 2012;60(1):7-14. DOI: 10.1111/j.16000757.2012.00452.x.

22. Drury TF, Garcia I, Adesanya M. Socioeconomic disparities in adult oral health in the United States. Ann N Y Acad Sci 1999;896:322-324. DOI: 10.1111/j.1749-6632.1999.tb08129.x.

23. Shabana. Tooth loss prevalence and risk indicators among adult people visiting community health centers in Nellore district, Andhra Pradesh: a cross-sectional study. J Indian Assoc Public Health Dent 2016;14(4):413-418. DOI: 10.4103/2319-5932.195829. Available from: http://www.jiaphd.org/article.asp?issn=2319-5932.

24. Joseph AG, Janakiram C, Mathew A. Prosthetic status, needs and oral health related quality of life (OHRQOL) in the elderly population of Aluva, India. J Clin Diagn Res 2016;10(11):ZC05-ZC09. DOI: 10.7860/ JCDR/2016/19298.8768. Available from: https://www.ncbi.nlm.nih. gov/pmc/articles/PMC5198447. 